\title{
Combates pela historiografia: a história política das ideias de Franco Venturi
}

\author{
Combates on historiography: \\ the political history of ideas of Franco Venturi
}

Breno Ferraz Leal Ferreira*

\section{RESUMO}

Neste artigo situaremos a obra de Franco Venturi na historiografia do século XX sobre o lluminismo. Iniciaremos com uma apresentação da trajetória do historiador italiano, mostrando a sua experiência de vida em relação às ideologias totalitárias do século. Na sequência, exporemos os debates historiográficos que tece no livro Utopia e reforma no lluminismo (1969), enfatizando suas críticas ao que denomina "tradição filosófica da Aufklärung alemã" e à "interpretação social do lluminismo". Deverá ficar claro que rejeita o marxismo como ferramenta para a compreensão das Luzes, manifestando preferência por abordagens que partam do indivíduo e de suas relações concretas. Por último, analisaremos suas ideias sobre as origens do socialismo/comunismo no século XVIII, discutindo as posições do autor sobre as ideias de Marx e o marxismo.

Palavras-chave: Franco Venturi. Historiografia. Iluminismo. Marxismo. Comunismo.

\section{ABSTRACT}

In this article we intend to situate the word of Franco Venturi in the Twentieth Century historiography of the about the Enlightenment. We will start with a presentation of the trajectory of the Italian historian, showing his life experience with the totalitarian ideologies of the century. Subsequently, we will expose the historiographical debate that he presents in the book Utopia and Reform in the Enlightenment (1969), emphasizing his critics to what he named "philosophical tradition of the german Aufklärung" and the "social interpretation of the Enlightenment". It must be clear that he rejects Marxism as an instrument to the understanding of Enlightenment, giving preference to approaches that depart from individuals and their concrete relations. Lastly, we will analyze Venturi's ideas about the origins of the socialism/communism in the Eighteenth Century, discussing his view on Marx's ideas and Marxism theory.

\footnotetext{
* Doutorando em História Social pela USP. Mestre em História Social (2009) pela mesma instituição e bolsista da Capes.
} 


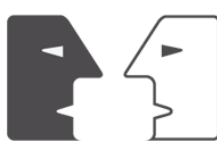

ANTÍTESES

Keywords: Franco Venturi. Historiography. Enlightenment. Marxism. Communism. 


\section{Franco Venturi: formação e trajetória de um militante ${ }^{1}$}

Temos em Franco Venturi (Roma-1914 - Turim-1994) um exemplo de historiador para quem o entendimento do passado (no caso, do Iluminismo) se relaciona diretamente com as suas próprias preocupações do presente. Em sua experiência concreta de vida não faltaram razões que justificassem a busca pela compreensão, dentro do domínio da história, da gênese do mundo em que vivia.

A política sempre esteve no centro de suas atenções, não somente por ter vivido desde pequeno o contexto de crise que decorreu à Primeira Guerra Mundial na Itália, que acabou por fazer ascender Mussolini ao poder (1922), mas também por razões familiares. Seu pai, Lionello Venturi (1885-1965), historiador da arte assim como seu avô, Adolfo Venturi (18561941), foi um dos únicos professores universitários italianos (no total de onze) que se negaram a jurar fidelidade ao regime fascista, o que o levou a ser demitido e se exilar, junto com a família, para a França, em 1932. Com apenas dezoito anos, Franco Venturi teve que concluir seus estudos em Paris, onde veio a se formar em História, na Sorbonne. Lá, já em 1933, engajou-se no movimento antifascista Giustizia e Libertà, formado por demais exilados italianos partidários de um socialismo reformista não marxista, entre eles aquele que lhe foi mais próximo, Carlo Rosselli (1899-1937).

Mas como se não bastassem seus problemas com o fascismo italiano, Venturi ainda viu a França ser ocupada pelos nazistas. Tentou se refugiar nos Estados Unidos a partir da Espanha, mas preso pelo regime franquista, foi entregue aos fascistas em 1941 e confinado até 1943 em Basilicata, no sul da Itália. Livre, estabeleceu-se no Piemonte, filiando-se ao Partido d'Azione, formado a partir do Giustizia e Libertà por intelectuais republicanos e socialistas independentes que lutavam como partisans em uma Itália ainda ocupada pela Alemanha. Após a dissolução do partido (1946), Venturi nunca mais se filiou a nenhum outro, mas seu engajamento ainda pode ser percebido por toda sua obra posterior, na qual é nítida uma preocupação com as questões políticas do presente, resultado da experiência concreta pela qual passou.

Não é por menos. Além de ter sido perseguido pelos fascistas, visto a França ocupada pelos nazistas e preso na Espanha franquista, ainda teve a experiência de viver, por duas ocasiões, na União Soviética de Stálin, muito embora lá de maneira voluntária e sem conturbações. Portanto, vivenciou concretamente aquilo que o século XX produziu de mais doloroso: os totalitarismos, tanto de esquerda quanto de direita.

Na França, contou nos estudos com a orientação de Daniel Mornet (1878-1954) - autor de clássica obra sobre as origens intelectuais da Revolução Francesa - e Henri Bédarida (1887-

${ }^{1}$ Os dados biográficos de Venturi foram retirados de dois textos: Florenzano (2003) e Woolf (1972). 
1957). O resultado foi a publicação de uma série de estudos sobre o Iluminismo, tema pelo qual desenvolveu enorme afinidade. Como observa Modesto Florenzano,

os iluministas, tal como vistos por Venturi, são todos intelectuais (com)bativos, constituem todos uma intelligentsia, à maneira de sua encarnação histórica mais radical e extrema, que foram os populistas e revolucionários russos de meados do século XIX e início do XX. São indivíduos livres, autônomos com relação seja à sociedade, seja ao Estado e com vontade, mais ou menos ardente, de a ambos reformar, porque o mundo no qual vivem é um mundo sem liberdade e, ao mesmo tempo, em mudança: o Antigo Regime absolutista, no caso dos iluministas e dos populistas, e o fascismo, no caso do próprio Venturi. Como lembrou um crítico, o mote de Venturi é que o intelectual, sob regimes opressivos, tem o dever de fazer política. (FLORENZANO, 2003, p.16)

Isso de certa forma explica o interesse de Venturi não somente pelo Iluminismo em geral, mas por autores e obras específicos do século XVIII. O interesse por Diderot resultou na publicação, em 1939, de sua primeira obra, Jeunesse de Diderot (de 1713 à 1753), que recebeu resenha elogiosa de Lucien Febvre nos Annales. Diz Florenzano (2003, p. 11-12):

Febvre tocava assim no cerne da motivação venturiana que foi descobrir em Diderot (e nele próprio) a necessidade quase que religiosa e o sentido ético da política, pois, não disse Diderot, em frase reproduzida por Venturi em mais de um de seus escritos: 'Imposez-moi silence sur la religion et le gouvernement, et jê n'aurai plus rien à dire'?

Fica clara identificação de Venturi pelas ideias e ações políticas dos homens do Iluminismo como Diderot. No mesmo ano, publicou ainda Dom Deschamps, Le vrai système ou Le mot de l'énigme métaphysique et morale, em parceria com Jean Thomas.

Porém, Venturi não tinha uma visão do Iluminismo restrita à França. Em conformidade com as concepções de Paul Hazard (1878-1944) - a quem considerava seu mestre -, Carl Becker (1873-1945) e outros (como veremos), seu Iluminismo é um fenômeno europeu, do norte ao sul, de leste a oeste, com desdobramentos na América. Interessavam-lhe em particular os iluministas italianos. Assim, antes de retornar à Itália e publicar Le origini dell'Enciclopedia, em 1946, Venturi, como escreveu Stuart Woolf,

looked back to the historical intuitions and heroic self-sacrifice of the young anti-fascist Piero Gobetti, who died after a fascist attack in 1926. It was Gobetti's brief sketches of two eighteenth-century Piedmontese rebels, Alberto Radicati di Passerano and Dalmazzo Francesco Vasco, who suffered exile and imprisonment for their heterodoxy, that were to lead Venturi to trace their ideas and experiences in impressive biographies. (WOOLF, 1972, p.viii). 
Sua pesquisa de doutoramento Dalmazzo Francesco Vasco (1732-1794) foi impedida de ser defendida em função da ocupação nazista da França. Posteriormente, veio a publicar diversos estudos sobre autores do Setecentos italiano como Pasquale Paoli (1725-1807), Cesare Beccaria (1738-1794), Pietro Verri (1728-1797), Antonio Genovesi (1712-1769) e Ferdinando Galiani (1728-1787), entre outros.

Como nos referimos anteriormente, Venturi passou duas vezes pela União Soviética. Em 1936, esteve brevemente em Moscou em busca de pistas sobre Diderot e o comunismo. De volta entre 1947 e 1950, pesquisou nas bibliotecas das cidades de Moscou e Leningrado, além de concluir seu aprendizado da língua russa que havia iniciado em Basilicata. Pelas mesmas razões que os iluministas do século XVIII lhe interessaram, a intelligentsia russa prérevolucionária lhe chamou a atenção. Tratava-se de estudar o momento de formação das ideias que levaram à Revolução de 1917. Nas palavras de Florenzano: "ninguém antes dele havia se preocupado em focalizar as diferenças e as afinidades entre o populismo (geralmente visto como um fenômeno típico da Rússia) e o socialismo tal como apareceu e se desenvolveu na Europa Ocidental" (FLORENZANO, 2003, p.9). De volta à Itália, país no qual viria a lecionar nas universidades de Cagliari, Gênova e Turim, publicou os resultados de suas pesquisas na União Soviética, isto é, as obras Il populismo russo (1952) e Il moto decabrista e i fratelli poggio (1956), livro sobre os decembristas no qual tecia considerações sobre a penetração das ideias iluministas na Rússia pós Catarina II. Segundo Woolf (1972, p. ix-x),

the faith of the Decabrists in a constitution, typical of late Enlightenment writers as Venturi points out, is directly linked to the preocupation of so many European conspirators about how to carry out a revolution without allowing it later to degenerate into Jacobin terrorism or Napoleonic tyranny.

Também fruto de seus estudos em Moscou e Leningrado, publicou a obra Esuli russi in Piemonte dopo il' 48, de 1959, na qual analisou o exílio do revolucionário russo Aleksandr Ivanovich Hezern (1812-1870) no Piemonte e a circulação de ideias que emergiram das Revoluções de 1848. Fica claro, portanto, que Venturi, mais do que um historiador do Iluminismo, foi um historiador da modernidade, preocupado com os rumos de sua própria época.

A circulação das ideias entre diferentes autores de diferentes países era uma preocupação recorrente de Venturi, e perfeitamente em conformidade com a concepção de Iluminismo de um historiador interessado em superar a visão dos historiadores italianos do início do século XX que insistiam no caráter autônomo do Iluminismo italiano (voltaremos a essa questão no próximo item). E, nesse aspecto, revelam-se mais do que preocupações a respeito de circulação de ideias políticas. Interessavam-lhe projetos de reforma não só política, mas também social e econômica no século XVIII, bem como a circulação de tais 
ideias. Tratava-se de buscar as origens dos próprios projetos reformistas e revolucionários de sua época - como ficará claro quando analisarmos seu livro Utopia e reforma no Iluminismo.

Exemplos do que estamos afirmando são seus textos "The Position of Galiani between the Encyclopaedists and the Physiocrats" (1960) e "Spanish and Italian Economists and Reformers in the Eighteenth Century" (1962) (VENTURI, 1972). No primeiro, o historiador trata da recepção da obra do economista italiano Ferdinando Galiani (1728-1787) no mundo intelectual parisiense em relação com a crise econômica pré-revolucionária, numa época em que lá se discutiam ideias fisiocratas e sobre livre-comércio. No segundo, compara a situação de declínio econômico entre duas regiões que maninham relações econômicas entre si, a Espanha do economista Gerónimo de Uztáriz (1670-1732) e a Itália de Antonio Genovesi (17121769), cujos escritos giravam em torno de questões filosóficas, políticas e econômicas. Essas questões, e outras tantas, permaneceram sendo estudadas por Venturi, que, entre 1969 e 1990, publicou as mais de quatro mil páginas que constituem os sete volumes de Settecento Riformatore (o oitavo ficou incompleto), dedicadas à Europa como um todo.

Os anos 1960 marcaram uma relativa mudança de suas posições políticas. Como afirma Florenzano, pouco a pouco "seu socialismo foi sendo sepultado pelo seu anticomunismo", ainda que "nunca deixando de ser radicalmente republicano, democrático e progressista" (FLORENZANO, 2003, p.14). Seja como for, é um grande mérito seu que esse anticomunismo nunca tenha em momento algum deixado de "levar em conta e de reconhecer a importância e o peso do econômico e do social, das classes e suas lutas" (FLORENZANO, 2003, p.24).

Portanto, o interesse pelo comunismo soviético do pós-guerra de certa forma o influenciou no abandono de uma ideologia ligada ao socialismo reformista em prol de uma postura mais próxima do liberalismo democrático.

\section{Combates pela historiografia}

Em 1969, Utopia e reforma no Iluminismo de Franco Venturi (2003) abre fogo contra o que seriam, no seu entender, as duas grandes tradições interpretativas das Luzes: a "tradição filosófica da Aufklärung alemã" e a história social do Iluminismo. Vejamos separadamente cada uma delas, analisando tanto a maneira como Venturi as concebeu quanto a relação que a sua obra teve com ambas. 


\section{A "tradição filosófica da Aufklärung alemã"}

A "tradição filosófica da Aufklärung alemã" a que se refere Venturi emergiu a partir dos anos 1920 e fazia parte de um movimento mais abrangente da historiografia que, ao mesmo tempo em que reagia contra uma interpretação nacionalista das Luzes herdeira do século XIX, apresentava concepções das Luzes que serviam como trincheira aos historiadores na luta contra a emergência dos totalitarismos. A obra de Franco Venturi pode ser enquadrada nesse movimento da historiografia.

Não por acaso, no período que sucedeu à Primeira Guerra Mundial (1914-1918) se formou uma geração brilhante de intelectuais se debruçou sobre a temática das Luzes. Entre os anos 1920 e 1930, o mundo assistiu à ascensão ao poder de Stálin na União Soviética, de Mussolini na Itália e Hitler na Alemanha, somente para se citar os casos mais emblemáticos. Para intelectuais como Julien Benda (1867-1956), Ernst Cassirer (1874-1945), Benedetto Croce (18661952), Paul Hazard (1878-1944) e o próprio Franco Venturi (1914-1994), tratava-se de estudar o fenômeno ilustrado para torná-lo, cada autor ao seu modo, forma de contestação aos totalitarismos (FERRONE; ROCHE, 1998, p.444-449). Para Venturi, assim como os outros intelectuais citados, o estudo do Iluminismo serviria, entre outros aspectos, para afirmar os princípios universais numa Europa fracionada e ameaçada pela ascensão dos totalitarismos (tanto de esquerda quanto de direita).

Na Itália de Venturi, o século XX se iniciou marcado fortemente por tendências nacionalistas. Autores como Carlo Calcaterra (1884-1952), Vittorio Cian (1862-1951) e Ettore Rota (1883-1958) compreendiam o Iluminismo como uma espécie de prelúdio ao Risorgimento do século XIX. Predominavam tentativas de provar o caráter autônomo da história italiana, ignorando suas relações com o resto da Europa (WOOLF, 1972, p.vii-viii). É nesse contexto que se verifica a importância de um historiador como Benedetto Croce. De certa forma conjugando liberalismo e conservadorismo, não deixou nunca de condenar com veemência as ideias políticas e os ideais considerados perigosos, o que lhe trouxe o interesse da parte de intelectuais antifascistas (FERRONE; ROCHE, 1998, p.446-447). Croce foi o introdutor do termo "Illuminismo" na língua italiana, termo que cunhou como tradução direta de "Aufklärung" (FERRONE; ROCHE, 1998, p.415). Aos olhos dele, o Iluminismo aparecia como um movimento espiritual que havia inspirado a ação de uma elite decidida a emancipar a sociedade e transformar as consciências (FERRONE; ROCHE, 1998, p.446).

Além da Itália, em outros países também se formaram, ao longo do século XIX e o início do XX, vertentes interpretativas nacionais próprias do Iluminismo. Significativas foram as tendências que se desenvolveram na França e na Alemanha. De maneira geral, a primeira discutia a relação entre as lumières e a Revolução de 1789 , geralmente entendendo o radicalismo revolucionário (o Terror jacobino) como fruto do pensamento dos philosophes, associados ao ateísmo e à descristianização, enquanto que a segunda se desenvolveu em função da necessidade de identificar uma tradição nacional unitária, e assim fazendo da 
Aufklärung uma via alternativa, contraposta à França, no processo de modernização do Ocidente (FERRONE; ROCHE, 1998, p.415-444).

Na França, em contraposição à "paixão nacionalista", Julien Benda propôs o regresso ao cosmopolitismo de Voltaire e à "paixão da razão" do século XVIII, em sua obra Discurso à nação francesa (1933) (FERRONE; ROCHE, 1998, p.444-445). Os intelectuais do continente deveriam denunciar a traição dos antigos ideais cosmopolitas e lutar como os philosophes haviam feito. Dois anos depois viria à luz a clássica obra de Paul Hazard, La Crise de la conscience européenne (1680-1715), seguida de Le pensée européenne au XVIIIe siècle, de Montesquieu à Lessing, publicada postumamente em 1946. Ambas as obras põem em relevo ideias e fenômenos comuns ao pensamento de diferentes autores iluministas de toda a Europa, com o intuito de superar as diversidades nacionais.

Na Alemanha, foi significativa a obra do filósofo Ernst Cassirer, um dos diversos autores para os quais o exílio para o exterior se tornou a única alternativa à ameaça nazista. Simpatizante dos princípios progressistas e democráticos da República de Weimar, Cassirer, com sua obra Die Philosophie der Aufklärung (1932), operou uma espécie de reabilitação do Iluminismo na Alemanha ante as interpretações românticas, entendidas por ele como superficiais. Para ele, o fenômeno ilustrado teve o mérito de ter revolucionado e modernizado a maneira de se conceber a filosofia, já que esta, por meio dele, havia se convertido no instrumento fundamental de que Kant havia falado, ou seja, garantir o uso público da razão em qualquer campo (FERRONE; ROCHE, 1998, p.447-448). O Iluminismo seria, para Cassirer, não um sistema coerente de ideias, mas uma mentalidade, uma forma de pensamento amparada num novo conceito de razão (FERRONE, 1997, p.179). As Luzes do século XVIII se voltariam contra o "espírito de sistema" característicos dos filósofos do XVII (CASSIRER, 2002, p.11).

Da leva de intelectuais alemães emigrados que acabaram por se transformar em referências dos estudos acerca do Iluminismo, devemos nos lembrar também de Peter Joachim Fröhlich (1923-), tornado Peter Gay nos Estados Unidos quando lá chegou com sua família perseguida pelo nazismo em 1941. Autor da clássica obra The Enlightenment: an interpretation (1966), Gay caracterizou as Luzes a partir de diferentes gerações de filósofos ilustrados. Apesar, das diferenças entre autores e gerações, Gay considera que formavam uma espécie de família, em função do que tinham em comum: estilos de pensamento, estratégias e carreiras em um ambiente cultural comum. Seu interesse, como ele mesmo diz, residia no encontro das ideias dos filósofos com a realidade (GAY, 1995, p.ix-xi).

As obras de Cassirer e Gay serão incluídas por Venturi dentro do que denominou "tradição filosófica da Aufklärung alemã" em Utopia e reforma no Iluminismo. Porém, antes de analisar as suas críticas a eles, cabe acrescentar outro importante nome que também será identificado a essa tradição: Carl Becker, autor da clássica obra The Heavenly City of the Eighteenth-Century Philosophers (1932) (BECKER, 1932). Sem incorrer no paradigma 
teleológico da leitura do Iluminismo a partir da Revolução, que havia, segundo Ferrone e Roche, dominado a historiografia anglo-saxã no século anterior, Becker explicava que seu objeto era um "clima de opinião internacional" formado por indivíduos que, independentemente de sua nacionalidade, tinham em comum um mesmo modo de interpretar a realidade (FERRONE; ROCHE, 1998, p.445). Todavia, podemos dizer que sua compreensão das Luzes refletia de certa forma seu conservadorismo político, já que para ele os filósofos iluministas demoliram a "Cidade de Deus de Santo Agostinho" apenas para reconstruí-la sob novas bases secularizadas. O Iluminismo não teria trazido algo de muito novo, portanto.

Venturi volta-se contra esses historiadores, porque todos eles teriam procurado dar uma resposta à questão posta pelo periódico Berlinische Monatsschrift em 1784 ("O que é Iluminismo"), o que faria com que incorressem no que chama "mito das origens". Tendência fortemente presente entre os alemães (iniciada por Kant, ao responder à questão proposta), mas não exclusivamente, ela seria caracterizada pela recorrência a uma "busca pelos princípios" das ideias para explicar o Iluminismo.

A principal crítica a Cassirer incide no fato de que se busca sempre as origens de ideias iluministas - sempre filosóficas e religiosas, mas nunca econômicas, políticas ou jurídicas , o que não ajuda muito em explicar o Iluminismo, já que lhe faltaria "ação política concreta", na expressão de Diderot (VENTURI, 2003, p.27-29). Como vimos, o Iluminismo se caracterizaria, para Cassirer, pela oposição ao "espírito de sistema" que marcou a filosofia seiscentista (Leibniz, Malebranche, Espinosa, Leibniz). Venturi concorda com Cassirer nesse ponto, pois o caráter fundamental do Iluminismo seria, segundo ele, a "vontade radical de não construir sistemas filosóficos" (VENTURI, 2003, p.29). Entretanto, em seu entender, o desenvolvimento das ideias iluministas no século XVIII nada mais seria do que uma espécie de releitura das ideias dos mesmos autores seiscentistas sob novas bases, ou melhor, sob novos sistemas filosóficos. Nesse sentido, Cassirer teria incorrido em contradição com a sua própria caracterização das Luzes, incorrendo ele mesmo no "mito das origens". A função dos historiadores deveria ser outra: ao contrário dos filósofos, aqueles deveriam nos dizer "como o rio abriu seu caminho, em meio a quais obstáculos e dificuldades", o que significa que é a função das ideias na história do período o que importa, e não de onde elas vieram (VENTURI, 2003, p.29).

Incorrendo também no "mito das origens" estaria também Carl Becker, cujo livro The heavenly city of the eighteenth century philosophers não passaria de "história retroativa". 0 historiador norte-americano, como vimos, enxergou nas Luzes da razão uma versão secularizada do pensamento cristão escolástico, também calcado na ideia de razão. Ou seja, para Venturi, Becker não soube captar o que o movimento ilustrado trouxe de novo, de "historicamente eficaz e fecundo" (VENTURI, 2003, p.31), apenas abordando-o a partir do que seriam suas raízes cristãs. 
Em seu entendimento, Peter Gay também não conseguiu escapar de explicar o Iluminismo recorrendo a personagens do passado, muito embora o elogie por não se deixar se levar por "esquemas filosóficos e ideológicos". No primeiro volume de sua obra The Enlightenment: An interpretation, os vultos dos autores gregos e romanos estariam por trás e explicariam, de certa forma, autores como d'Holbach e Diderot, o que mostraria "como é difícil sair do círculo mágico da tradição da Aufklärung alemã" (VENTURI, 2003, p.31-32).

\section{A "história social do Iluminismo"}

Para além desses importantes intelectuais, cujas obras (com a exceção da de Peter Gay) foram publicadas ainda no Entreguerras, é importante destacar que em Utopia e reforma no Iluminismo Venturi elege também como interlocutores autores marxistas ou autores que dialogam com o marxismo na compreensão do Iluminismo.

De certa forma, o marxismo pode ser compreendido também como uma ideologia iluminista, pois herdeira do século das Luzes. Venturi vai se posicionar a este respeito, apontando que, de fato, o marxismo derivou do Iluminismo. Porém, vai deixar claro suas preferências pelas vertentes menos radicais do século XVIII.

Sem entrar em detalhes aqui sobre esse debate, ressalte-se que, no campo conservador, a discussão em torno das doutrinas de Marx e Engels se acentuou em função da expansão socialista do século passado. Dando continuidade à relação consolidada no século XIX que interpretava o Iluminismo à luz da Revolução Francesa, e enfatizando principalmente o caráter antirreligioso das Luzes, o pensamento conservador valeu-se de uma associação entre a Revolução de 1789 e a Revolução de 1917 para criticar o comunismo e o marxismo. Comumente fazia-se uma conexão que ligava Rousseau ao totalitarismo (SKINNER, 2007, p.138) e a Robespierre e este a Marx e à União Soviética. Ou seja, a relação direta discutida pela intelectualidade francesa no século XIX entre Iluminismo e Revolução foi, no século $\mathrm{XX}$, aprofundada em função de um novo tipo de revolução cujas raízes também incidiriam no Iluminismo, por meio de sua vertente revolucionária.

Em diálogo com o marxismo, a chamada "história social do Iluminismo" se constituiu como uma vertente interpretativa das Luzes nascida nos anos 1950 e 1960 que tinha como meta, de acordo com Ferrone e Roche, superar todas as antigas formas de história intelectual que haviam explorado até então o nexo tradicional entre Iluminismo e Revolução. Entre as tradições historiográficas que se encontraram em sua gênese, estava a história social e econômica do Antigo Regime, teorizada e praticada pelos historiadores ligados à revista dos Annales (FERRONE; ROCHE, 1998, p. 453). François Furet (1927-1997) é apontado por Venturi como um dos historiadores relacionados a essa corrente. 
A história social do Iluminismo partia da primazia do social e do econômico como esferas do saber. O rechaço dos historiadores dos Annales à história política contribuiu para desprestigiar outros campos da historiografia, como a história das ideias. Na França, somente os historiadores da chamada terceira geração dos Annales vieram a reabilitar a história política, mas muitas vezes em função de uma recusa da história social. Tome-se o exemplo do próprio François Furet, que de historiador marxista e membro do Partido Comunista deixou posteriormente a história social de lado em favor da história política. Tornando-se anticomunista, distanciou-se do grupo dos Annales e adotou a política como a esfera privilegiada de suas reflexões, principalmente a Revolução Francesa, mas também a Revolução Russa e o comunismo soviético (FURET, 1995). Não é preciso dizer que se tornou um historiador "revisionista", crítico contundente da historiografia jacobina e da fase do Terror da Revolução Francesa - Terror este que, para a historiografia revisionista, comportava em si a ideologia revolucionária cujas origens se encontrariam na "soberania popular" de Rousseau - germe do totalitarismo (VOVELLE, 2004, p.83-103).

O problema maior identificado por Venturi na interpretação social do Iluminismo é o seu "caráter marxista". O marxismo é rechaçado como uma ferramenta inadequada de compreensão do passado. O entendimento do Iluminismo por parte de vertentes do marxismo que o entendiam como "ideologia da burguesia em desenvolvimento" é recusado como uma visão limitada e insuficiente para explicar aquele fenômeno histórico (VENTURI, 2003, p.40-41). Essa concepção caricatural das Luzes teria em Lucien Goldmann (1913-1970) um de seus principais representantes. Venturi se incomoda com abordagens que partem de classes, por considerar que, adotando esse procedimento, não se parte da realidade concreta, do indivíduo, suas ideias e relações econômicas e políticas, muito embora não renegue de todo a história social. Daí seu apreço por estudos de autores enquanto indivíduos e suas obras. Mesmo análises de historiadores marxistas como Jacques Proust (1926-2005), que se fundamentariam na "efetiva realidade", não são totalmente aceitas, pois limitadas pelo próprio procedimento metodológico que adotam. No fundo, Venturi aponta limites na observação da realidade concreta justamente em uma teoria que pretende partir dela, ou seja, das estruturas socioeconômicas. Partir da realidade concreta, para Venturi, significa partir dos indivíduos, de suas ideias enquanto ainda não se tornaram estruturas mentais, em seu momento criativo e ativo. A simples aplicação de uma teoria já pronta a um objeto, no caso o Iluminismo, empobrece a análise.

Por acreditar que se deve partir do indivíduo como realidade concreta e não de esquemas pré-concebidos, Venturi tece uma crítica à pretensão de se fazer uma "história total", ou seja, "a visão da sociedade como uma estrutura global capaz de revelar a sua lógica interna, a lei da própria existência se submetida a um instrumento interpretativo adequado, seja ele a luta de classe, a quantificação ou o estruturalismo" (VENTURI, 2003, p.49). Para o historiador, ao se proceder dessa forma incorre-se sempre no risco de distorcer o julgamento histórico, transformando-o em filosofia da história. Observa-se aí sua discordância em 
relação aos métodos das ciências sociais, novamente em relação ao marxismo, mas também ao estruturalismo em voga nos anos 1960.

Se metodologicamente o marxismo é recusado como ferramenta de compreensão do Iluminismo, o caminho inverso é o que lhe agrada. De acordo com ele, é a gênese do comunismo - logo, o marxismo -, que deve ser buscada no Iluminismo. Marx e Engels deveriam ser vistos como ponto de chegada, não de partida:

O risco da história social do Iluminismo, especialmente evidente na França atual, é o de estudar as ideias quando já se tornaram estruturas mentais, sem nunca captar o momento criativo e ativo, é o de examinar a estrutura geológica do passado, menos, precisamente, o húmus sobre o qual os frutos e as plantas crescem. O resultado historiográfico é, com frequência, o de confirmar com grande luxo de métodos novos aquilo que já se sabia [...]. (VENTURI, 2003, p.46-7)

Temos, portanto, clara a maneira como Venturi enxerga a conexão entre o Iluminismo e o tempo presente: é do Iluminismo que se deve partir pra se compreender o marxismo, e não o contrário. Curiosamente, um dos exemplos de historiadores que fornece para exemplificar esse tipo de abordagem metodológica é François Furet (VENTURI, 2003, p.47), que como apontamos anteriormente viria a abandonar posteriormente a história social e o marxismo em suas análises da Revolução Francesa em prol de uma história política carregada de antimarxismo e anticomunismo.

É também no domínio da política que Venturi constituiu seu interesse principal. Declaradamente, intenciona fazer uma "história política do Iluminismo", com a qual se chegará, a partir do estudo do impacto do republicanismo, "ao coração mesmo da relação entre utopia e reforma, que examinaremos de um só ponto de vista mas que me parece significativo: o do direito de punir" (VENTURI, 2003, p.51). Por isso, a seguir nos deteremos mais afixamente no capítulo "O direito de punir".

\section{As origens iluministas do comunismo}

Utopia e reforma no Iluminismo foi o resultado das conferências que Venturi realizou nas George Macaulay Trevelyan Lectures, na Universidade de Cambridge, em 1969. Até essa data, a obra de Venturi era conhecida basicamente apenas na França e na Itália, muito embora tenha apresentado um "relatório" sobre o Iluminismo no $\mathrm{XI}^{\circ}$ Congresso Internacional de Ciências Históricas de Estocolmo (1960). Nos países de língua inglesa, porém, o pouco que se conhecia de sua obra se devia à tradução de Il populismo russo (Roots of Revolution, de 1964). 
O objetivo declarado de Venturi na obra é "tentar colocar o problema do impacto da tradição republicana no desenvolvimento do Iluminismo" (VENTURI, 2003, p.51). O autor pretende discutir a questão da tradição republicana a partir da experiência concreta vivida por cidades e nações na modernidade. No fundo, a intenção é demonstrar a distância entre a realidade do século XVIII e o mundo antigo. O mote de Horácio, Sapere aude!, tornado mote do Iluminismo por Kant, não explica o mesmo, muito embora ainda sirva para revelar "a emergência e a mudança das ideias e dos estados de espírito" (VENTURI, 2003, p.39).

Nesse sentido, o primeiro capítulo ("Reis e repúblicas nos séculos XVII e XVIII") parte da premissa de que o pensamento republicano moderno não deriva de Péricles ou Tito Lívio, mas da experiência concreta das cidades italianas, flamengas, alemãs, além das nações (Holanda, Suíça, Inglaterra e Polônia) que reinterpretaram a tradição clássica. O segundo ("Os republicanos ingleses") e o terceiro ("De Montesquieu à Revolução") capítulos dão sequência ao primeiro, discutindo o republicanismo na Inglaterra e na França, principalmente. No caso inglês, o autor descortina a conexão entre a luta política dos republicanos (para além das revoluções do século XVII) e o nascimento do livre pensamento, na passagem da tradição republicana para a gênese do Iluminismo (VENTURI, 2003, p.136). Já para o caso francês, Venturi esquadrinha a influência dos livre-pensadores como Shaftesbury nos iluministas franceses, como em Diderot (VENTURI, 2003, p.144). A análise vai até o momento das revoluções (americana e francesa), quando a "constituição dos Estados Unidos da América abre uma nova época na história das repúblicas e, com a Revolução Francesa, se fecha o ciclo dos problemas que aqui procuramos examinar" (VENTURI, 2003, p.178).

O último capítulo ("Cronologia e geografia do Iluminismo") é resultado da tentativa de Venturi de "olhar para a Europa das Luzes no seu conjunto, procurando captar seu ritmo e fixar seus limites" (VENTURI, 2003, p.217). Embora veja o Iluminismo como um fenômeno europeu, é importante destacar as diferenças entre Venturi e seu mestre Paul Hazard: em primeiro lugar, apesar de também enxergar a origem das Luzes no início do século XVIII, Venturi considera que no Iluminismo mesmo muito pouco manteve das discussões oriundas da "crise de consciência europeia", o período (1680-1715) em que, segundo Hazard, gestaram-se as principais ideias iluministas (HAZARD, 1948); e em segundo lugar, o historiador italiano procurava enxergar as ideias a partir de sua concretude, inseridas na política, economia e sociedade de seu tempo, estando muito mais enraizadas na realidade do que da maneira como concebeu Hazard.

Mas é no quarto capítulo ("O direito de punir") que o autor desenvolve uma discussão sobre os "autores comunistas/socialistas" do século XVIII. Estes seriam ligados a uma tradição de pensamento utópico pré-revolucionário na França. Trata-se do capítulo em que mais bem coloca em relevo as questões que mais lhe tocavam, ou seja, as relativas às (origens das) ideologias contemporâneas, reafirmando Venturi sua proposta de escrever 
uma "história política das ideias", ou "história política e não apenas ideológica das Luzes" - e não, como era comum, uma história das ideias políticas.

A atenção em relação às questões concretas de seu tempo se revela pelos historiadores com os quais sente afinidade. É o caso do historiador conservador (e antimarxista) britânico Lewis Bernard Namier (1888-1960). Namier revolucionou os estudos sobre a política inglesa do século XVIII, tendo como alvo principal a historiografia whig. Venturi admirava a visão realista de Namier, muito embora discordasse de seu entendimento depreciativo em relação às ideias e ideologias (FLORENZANO, 2003, p.24). Venturi, ao contrário, era um historiador das ideias, e seu engajamento não poderia diminuir a importância e o valor das ideologias. Namier nasceu em território russo que atualmente faz parte da Polônia, a mesma região de onde provieram outros historiadores valorizados pelo historiador italiano, como Bronislaw Baczko (1924-), assim como ele autor de estudo sobre Dom Deschamps. Por isso, diz Venturi (2003, p.187):

Não é certamente por acaso que os melhores estudos na matéria [...] provenham da Polônia, ou que os melhores estudos sobre as ideias socialistas na véspera da Revolução Francesa, ou sobre Babeuf ou Fourier [...] provenham da Rússia. O problema do nascimento e da transformação da utopia no Setecentos não pode não ser vivo nesses dois países.

A "matéria" a que se refere Venturi é a utopia. "Utopia e reforma" são os temas do livro. A utopia é a ideia, o sonho. Seu interesse reside em estudar a passagem da utopia para a realidade, do "sonho individual ao movimento comunista" (VENTURI, 2003, p.185). No Iluminismo, projetos reformistas pretendiam materializar a utopia. No século $\mathrm{XX}$, era a revolução o meio com o qual se acreditava possível transformar o sonho em realidade. Porém, para ele as origens das ideias comunistas estão no Iluminismo, antes mesmo do que em Marx e Engels. Vimos que, para Venturi, Marx deveria ser ponto de chegada, não de partida. Venturi põe-se a estudar então a origem do comunismo no século XVIII.

Nesse sentido, cabe perguntar se Venturi não incorre naquilo que criticou, ou seja, no mito das origens para explicar o advento do pensamento marxista e do comunismo do século XX. Devemos nos atentar, então, para a maneira como enxerga a relação entre ideias comunistas do século XX e ideias comunistas do XVIII, considerando sua afirmação de que toda a idade das Luzes não é compreensível sem o elemento utópico,

que às vezes parece marginal, mas que na realidade é um dos resultados mais irreversível, imutável e duradouro que o século XVIII transmitiu ao XIX, uma daquelas formas mentais que, uma vez fixadas e formadas, não mais irá se dissolver senão depois de longas e difíceis provas e tentativas, senão em contato com a efetiva realidade de um longo e 
complexo processo histórico. Depois da metade do Setecentos, a ideia de que a abolição da propriedade pudesse mudar as próprias bases da convivência humana, abolir toda moral tradicional, toda política do passado não mais desaparecerá dos espíritos dos contemporâneos. (VENTURI, 2003, p.185)

Se o Setecentos transmitiu ao século XIX (subentende-se que especialmente a Marx e Engels) uma "forma mental", pode muito bem ter transmitido-a também ao século XX. Nesse sentido, o século XX representa nada mais do que a continuidade das ideias iluministas? Não há descontinuidade de ideias entre estes períodos?

Venturi examina a questão da utopia e reforma a partir da análise da obra do jurista milanês Cesare Beccaria (1738-1794), Dei delliti e delle pene (Dos delitos e das penas, 1764) e de sua recepção por diversos autores. Beccaria foi, segundo o historiador, o primeiro autor a separar Estado e Igreja em matéria penal. Ao Estado "caberia a tarefa de avaliar e ressarcir o dano que a infração da lei havia acarretado ao indivíduo e à sociedade" (VENTURI, 2003, p.189). A Igreja, se assim desejasse, que se ocupasse dos pecados. No pensamento de Beccaria se misturam as duas coisas, utopia e reforma, o que refletiria o próprio pensamento do século. Para Venturi, Beccaria mistura o ímpeto igualitário de Rousseau com o racionalismo do Barão de Holbach (1723-1789).

O historiador italiano traça uma genealogia do pensamento utópico. Este se desenvolve a partir de meados do século XVIII, constituindo Morelly (1717-1782?) a primeira expressão do comunismo francês, ecoando mais para frente na Conjura de Graco Babeuf (1796). O "entusiasmo social" perpassa, segundo Venturi, os autores da Enciclopédia ao debaterem questões como a justiça, equidade e o banimento das distinções entre o "teu e o meu", entre eles Rousseau e o seu "ímpeto igualitário". Fez parte do pensamento dessa corrente comunista o horror à violência e à crueldade, e aí chegamos a Beccaria - provavelmente o primeiro autor a ser chamado de "socialista" em língua moderna. Para ele, a razão deveria dominar o seu igualitarismo. A realização da utopia somente seria possível, no entanto, a partir de um conceito utilitário de sociedade, em que o grau de utilidade medisse todas as ações humanas. Assim, a alternativa ao uso da violência como punição ao criminoso viria por meio de uma reforma que partia da ideia de que "toda sociedade devia tender 'à máxima felicidade dividida pelo maior número"' (VENTURI, 2003, p.191). As penas não deveriam, portanto, exercer somente a tarefa de punir o fora da lei, mas também de ser útil para o resto da sociedade. Concretamente, Beccaria propunha que a pena de morte fosse substituída pelo trabalho forçado.

A partir daí, o autor analisa a receptividade da obra de Beccaria, especialmente na França. Sua preocupação é entender como que os iluministas sentiram o dilema "utopia ou reforma" (VENTURI, 2003, p.198), a partir da tradução francesa - e alterada - feita por Morellet (1727-1819). O lado utópico de Beccaria não impressionou Voltaire (1694-1778), que valorizou mais na obra do jurista italiano o sentido de aperfeiçoamento das leis e o que lhe 
poderia proporcionar de crítica à religião. Já Diderot adotou uma postura incerta em relação a Dei delliti e delle pene: o que parece é que o fracasso das tentativas de reformas durante o reinado de Luís XVI (1774-1792) foi acompanhado de uma perda de esperanças em relação a estas por parte do grande nome da Enciclopédia. Esse pessimismo é exposto por Venturi (2003, p.206-207) na seguinte afirmação:

\begin{abstract}
Diderot não pretendia evidentemente, e ele mesmo o afirma, justificar de alguma maneira a crueldade da justiça tradicional. Pretendia, pelo contrário, chamar a atenção sobre a [...] 'multidão de inconvenientes que são igualmente graves e aos quais não se presta nenhuma atenção'. Poderíamos dizer que a consciência social, que em Beccaria se concentrava em torno dos cárceres e às forcas, tendia, em Diderot, a recobrir todos os aspectos da convivência humana.
\end{abstract}

Para Venturi, Diderot assumia cada vez mais uma postura de "sociólogo", em função do distanciamento com a qual tratava o objeto. Sua descrença em relação à humanidade marcaria uma diferença em relação a Beccaria:

\begin{abstract}
Diderot acabava assim por desesperar da possibilidade de salvar quem estava no caminho do delito. Segundo Beccaria, ao contrário, não eram as categorias sociais que deviam guiar a justiça e nem mesmo as morais, quaisquer que fossem, mas a pura e simples vontade de não matar, de não continuar assim as lutas do estado de natureza, de não quebrar dessa maneira as próprias bases de uma convivência social tal como ele a concebia. (VENTURI, 2003, p.209).
\end{abstract}

Ou seja, temos claro que Diderot teria abandonado por completo a concepção beccariana, no que foi acompanhado por outros philosophes parisienses. Teria vindo dele mesmo, Diderot (ou de Morellet), a ideia de se fazer dos condenados verdadeiros escravos, o que, além de ter uma vantagem econômica, possibilitaria também que se demonstrasse a falsidade do preconceito da transmissibilidade dos vícios (vantagem científica amparada no utilitarismo). Linguet (1736-1794), baseado em Facchinei (1725-?), denunciou como hipocrisia a proposta do trabalho forçado, pois somente a violência, a punição pela forca, seria um instrumento válido contra a desigualdade social, se usada contra ricos e nobres. Numa sociedade dividida entre miseráveis e opulentos, não haveria distinção entre o trabalho do pobre e o trabalho do condenado a serviços forçados. Mably considerava que a natureza tinha feito os homens iguais, mas que havia na sociedade obstáculos que impediam a comunidade de bens. Numa sociedade assim, abandonar a pena de morte seria impensável.

Segundo Venturi, esse tipo de raciocínio, o da morte da utopia e da aceitação do duro realismo das leis de uma sociedade injusta, acabou por vencer o debate naqueles anos prérevolucionários. O autor fecha o capítulo com uma proposição emblemática: 
Basta abrir a Encyclopédie méthodique, no volume sobre a Economie politique, publicado em 1788 , lá onde se discutia De la peine de mort, para captar este supremo cansaço diante das reformas, este ceticismo e o agora triunfante realismo, logo antes que a revolução tivesse início. Momento de bonança antes da tempestade, equilíbrio aparente antes que se recobrisse na França e na Europa um novo ciclo nos contrastes e nas relações entre utopia e reforma. (VENTURI, 2003, p.215).

Temos aí uma conexão entre Iluminismo e Revolução. Venturi sugere que o caminho revolucionário foi a única saída em face do fracasso das reformas. A utopia morreu junto com as tentativas reformistas. Ou melhor, a Revolução fechou um ciclo. Outro ciclo de utopias e reformas estaria por vir, no século XIX. O que exatamente isso quer dizer? Trata-se de uma possível resposta à questão por nós colocada sobre continuidades e rupturas na época moderna? Venturi parece conceber a modernidade como uma sucessão de projetos reformistas e revolucionários, que mantém relações de rupturas e continuidades ao mesmo tempo. Afinal, Marx não foi o primeiro a conceber que desigualdade social era fruto da desigualdade de propriedades. Mas ao não avançar a análise para além do século XVIII, fica apenas sugerida a conexão direta com o filósofo alemão e, ainda, com as revoluções comunistas do século XX.

\title{
Conclusão: Mito das origens?
}

\begin{abstract}
A necessidade prática, que está no fundo de todo juízo histórico, dá a toda história o caráter de 'história contemporânea', porquanto, por muito e muito distantes que pareçam cronologicamente os fatos por ela referidos, a história se relaciona sempre com a necessidade e a situação presentes, nas quais aqueles fatos propagam suas vibrações (CROCE, 1962, p.14).
\end{abstract}

A frase acima, proferida por um dos mestres de Venturi, Benedetto Croce, no livro $A$ História como Pensamento e Ação, parece sintetizar bem o significado das obras do grande historiador do Iluminismo e, em especial, de Utopia e reforma no Iluminismo.

A "história política das ideias" e a "ação concreta" que apregoa Venturi se relacionam claramente com sua experiência de vida e do momento histórico em que viveu. Ou seja, com a "necessidade e situações presentes". Muitos elementos presentes na obra que aqui analisamos permitem afirmar não somente o seu antimarxismo, mas também seu anticomunismo - seja este no século das Luzes ou no século em que o autor viveu. Chega a ser difícil não enxergar o seu antimarxismo como decorrência do anticomunismo. 
Há, portanto, na obra uma relação entre o Iluminismo, o marxismo e o comunismo do século XX. Sendo assim, a pergunta que fica é se o autor incorre em "mito das origens", ou seja, se as origens iluministas do comunismo explicam os eventos do século passado.

Ora, vimos que Venturi critica os autores da "tradição filosófica da Aufklärung alemã" por incorrerem nesse mesmo mito das origens. Para ele, apontar a origem das ideias não serve para explicar a função que elas tiveram naquela sociedade do século XVIII, pois nada dizem sobre a política ou a economia da época. Nesse sentido, para respondermos apropriadamente à questão, seria necessário que tivéssemos em mãos uma análise de Venturi dos temas relativos ao século XX, coisa que o autor não faz na obra que discutimos. Porém, como dissemos, existem muitos indícios em Utopia e reforma no Iluminismo que nos sugerem que a resposta poderia ser afirmativa.

Assim como a utopia posta em prática no século XX não levou ao mundo idealizado pelos comunistas, a utopia no século XVIII não passava de "fantasia social" (VENTURI, 2003, p.209), ou seja, o autor apresenta um claro juízo de valor. Chega a ser curioso que o momento em que utiliza essa forte expressão seja em meio aos comentários que faz em relação às propostas que os iluministas franceses de imposição de trabalhos forçados e uso dos condenados para fazer experiências médicas. Isso faz lembrar, de certa forma, os gulags soviéticos, Auschwitz e as "experiências médicas" que resultaram em tantas vítimas em países totalitários durante o século XX.

Não se pode negar que seu anticomunismo é acompanhado de uma rejeição ao marxismo. Venturi recusa o arcabouço teórico marxista como ferramenta para a compreensão do movimento das Luzes, em seus aspectos econômicos, sociais e políticos. Ele prefere sempre análises que partam do indivíduo e das relações concretas estabelecidas entre ele e o mundo em que vive, como uma alternativa a abordagens que partam de classes ou que apliquem esquemas interpretativos pré-concebidos (como seria o caso do marxismo). As próprias ideias de Marx e Engels deveriam ser vistas como ponto de chegada, ou seja, como resultantes do Iluminismo. Ele chega mesmo a se referir com tom de lamento ao próprio advento da "nova ciência sociológica" (VENTURI, 2003, p.207) no final do século XVIII, identificando-a a um dos autores que teriam adotado essa perspectiva naquela época, ou seja, aquele que foi talvez a sua principal referência iluminista em termos de pensamento: Diderot; mas ao Diderot de idade mais avançada, com outro pensamento, que não o de sua juventude.

Também se deve lembrar de sua preferência manifesta por historiadores do século XVIII cuja experiência de vida se relaciona de alguma forma com a vivência no Império Russo, como é o caso de Lewis Namier e Bronislaw Backzo. Para Venturi, a experiência de vida concreta lhes dava vantagem para compreender as ideias (socialistas) anteriores à Revolução Francesa. Trata-se de mais um elemento que aponta no sentido de uma continuidade entre o ele chama de "socialismo iluminista" e o socialismo soviético. 
Portanto, a "história política das ideias" de Venturi apresenta certas características que a aproximam da renovação da história das ideias e da história política dos anos 1960 e 1970 então em voga. Se, por um lado, Utopia e reforma no Iluminismo apresenta semelhanças de cunho ideológico com a historiografia revisionista da Revolução Francesa (Furet), avançando de maneira inovadora sobre os temas que enfatizamos nesse artigo (isto é, sobre as ideias socialistas do século XVIII), por outro abortou temas como o republicanismo inglês e sua influência no Iluminismo, que se tornaria o grande tema de historiadores da chamada escola de Cambridge (local onde Venturi proferiu as conferências que deram origem ao livro) como Quentin Skinner e John Pocock especialmente a partir dos anos 1970.

\section{Bibliografia}

BECKER, Carl L. The heavenly city of the eighteenth century philosophers. New Haven \& London: Yale University Press, 1932.

CASSIRER, Ernst. La filosofia de la Ilustración. Tradução de Eúgenio Ímaz. 3. ed. México: Fondo de Cultura Económica, 2002.

CROCE. Benedetto. A História - Pensamento e ação. Tradução de Darcy Damasceno. Rio de Janeiro: Zahar Editores, 1962.

FERRONE, Vincenzo. O Homem de Ciência. In: VOVELLE, Michel. O Homem do Iluminismo. Lisboa: Editorial Presença, 1997.

FERRONE, Vincenzo; ROCHE, Daniel. Historia e historiografia de la Ilustración. In:

----------Tradução de José Luis Gil Aristu. Diccionario histórico de la Ilustración. Madrid:

Alianza Editorial, 1998.

FLORENZANO, Modesto. Apresentação. In: VENTURI, Franco. Utopia e reforma no Iluminismo. Tradução de Modesto Florenzano. Bauru: EDUSC, 2003.

FURET, François. O passado de uma ilusão: ensaios sobre a ideia comunista no século XX. Tradução de Roberto Leal Ferreira. São Paulo: Ed. Siciliano, 1995.

GAY, Peter. The Enlightenment: an interpretation. The rise of modern paganism. W. W. Norton \& Company, 1995.

HAZARD, Paul. A crise da consciência europeia (1680-1715). Tradução de Óscar de Freitas Lopes. Lisboa: Edições Cosmos, 1948.

SKINNER, Quentin. Significado y comprensión em la historia de las ideas. In: Lenguaje, política e historia. Universidad Nacional de Quilmes Editorial, 2007. 
VENTURI, Franco. Italy and the Enlightenment. Studies in a Cosmopolian Century. Editado por Stuart Woolf. Tradução de Susan Corsi. London: Longman, 1972.

VENTURI, Franco. Utopia e reforma no Iluminismo. Tradução de Modesto Florenzano. Bauru: EDUSC, 2003.

VOVELLE, Michel. Combates pela Revolução Francesa. Tradução de Maria Lucia Panzoldo. Bauru: EDUSC, 2004.

WOOLF, Stuart. J. Introduction. In: VENTURI, Franco. Italy and the Enlightenment. Studies in a Cosmopolian Century. Editado por Stuart Woolf. Traduzido por Susan Corsi. London: Longman, 1972. 